\title{
New piezoelectric composites based on isotactic polypropylene filled with silicate
}

\author{
Halina Kaczmarek $^{1} \cdot$ Bogusław Królikowski $^{2} \cdot$ Ewa Klimiec $^{3} \cdot$ Jolanta Kowalonek $^{1}$
}

Received: 4 November 2016 / Accepted: 30 December 2016 / Published online: 13 January 2017

(C) The Author(s) 2017. This article is published with open access at Springerlink.com

\begin{abstract}
Polymeric cellular composites are very important materials in modern electronics because they can be used as piezopolymers due to low specific weight, good thermal resistance and high value of piezoelectric constant $d_{33}$. The aim of this work was to obtain and characterize the cellular polypropylene (PP) composites as materials designed for microelectronics. PP has been modified by addition of commercial silicate filler and the obtained materials were extruded. Then, the composites were subjected to electric field for polarization. Effect of the filler content on the structure and physicochemical properties of the composites have been investigated. The following experimental methods have been applied: SEM, XRD, thermogravimetry, tensile tests and measurements of voltage and electric charge accumulated in the polymer. The piezoelectric constant and stability of piezoelectric properties were also determined. It was found that the growth in the filler content in the polymer causes the increase in the film porosity and the degree of PP crystallinity that reaches $70 \%$ for the PP sample with $10 \%$ of the filler. Young's modulus increased also in the presence of the filler. Moreover, the thermal stability of the composites was improved compared to neat PP. The piezoelectric constant of the composites was about $200 \mathrm{pC} / \mathrm{N})$.
\end{abstract}

Halina Kaczmarek

halina@umk.pl

1 Faculty of Chemistry, Nicolaus Copernicus University in Toruń, Gagarina 7 st., 87-100 Toruń, Poland

2 Institute for Engineering of Polymer Materials and Dyes Toruń Division, M. Skłodowskiej-Curie 55 st., 87-100 Toruń, Poland

3 Institute of Electron Technology - Kraków Division, Zabłocie 39 st., 30-701 Kraków, Poland

\section{Introduction}

Modern technologies often require application of polymer nanocomposites with special properties. The polymers with piezoelectric properties are the composites, which may successfully replace ceramic piezoelectric materials. These polymeric materials have undeniable advantages such as low density (thus, the products are very light), insulating properties, the flexibility, which can be modified over a wide range, and also ease of processing by conventional methods. Although piezoelectric polymers have been extensively studied, the phenomena accompanying the piezoelectric effect are not fully explained. Among the polymer materials having such properties, poly(vinylidene fluoride) (PVDF) stands out. PVDF is currently used in a production of microelectronic devices, unfortunately, it is too expensive to be used on a large scale, and urgently we are looking for cheaper alternatives.

The major problem from the point of view of practical applications of electroactive polymers is to obtain materials with permanent polarizability, which is greatly dependent on the morphological structure and the degree of crystallinity of the components. Moreover, piezoelectric materials should be characterized by proper thermal stability, which also determines their usefulness in contemporary technologies.

It is known that polyolefins, readily accessible, inexpensive polymers produced on a large scale, can be suitably modified in a simple way in order to impart piezoelectric properties [1-7]. Addition of inorganic or organic substances to polymeric matrix is an effective way to obtain electroactive polymers. Physical modification of such systems (orientation, corona discharge or the action of UV radiation) leads to the accumulation of electric charges and creates electrets. 
As stated, the special morphology of the sample, in particular cellular structure characterized by the presence of air voids in a matrix, allows us to obtain materials with large values of the piezoelectric constants. In such cavities, the electric charge is entrapped, which results in formation of permanent electric dipoles [5-9].

An interesting way to increase the piezoelectric activity of PP film is exposure to high pressures (using air or nitrogen) and higher temperatures in double expansion process. For instance, conducting the whole process in two pressure expansions: at temperatures from 20 to $80^{\circ} \mathrm{C}$ and pressure of $2 \mathrm{MPa}$ for the first process and temperature between 80 and $90{ }^{\circ} \mathrm{C}$ and pressure of $0.4 \mathrm{MPa}$ in the second process, one can acquire larger voids and a decrease in Young's modulus for PP films, which leads to the growth in $d_{33}$ to approx. $1000 \mathrm{pC} / \mathrm{N}[3,4]$.

Recent work regarding piezoelectric composites of polypropylene with kaolin showed that durable electrets can be formed by polarization in a constant and high electric field ranging from 100 to $125 \mathrm{~V} \mathrm{\mu m}^{-1}$ [10]. However, the influence of preparation method, morphology, cellular structure and crystallization degree on mechanical and piezoelectric properties of composites has not been yet well understood.

The objective of this work was to determine the composition and the method of preparation of piezoelectric materials based on isotactic polypropylene (i-PP) and selected silicate filler as well as characterization of theirs properties required for application in electronic industry.

Morphology and mechanical properties of the obtained composites were determined using SEM and standard tensile test, respectively. X-ray diffraction and thermogravimetric analysis were performed in order to study the crystallinity and thermal stability of the systems. To induce the piezoelectric properties, the composites were subjected to polarization under the influence of an electric field. The piezoelectric charge and voltage have been measured for 3 months, also after aging at elevated temperature.

It is expected that the filled i-PP can be a valuable material for the production of biomedical sensors because it is a flexible polymer, easy in processing and capable of forming any shapes. The most important task is to find suitable filler, which will provide the required cellular structure and piezoelectric properties of the composites.

\section{Experimental}

\subsection{Materials}

Isotactic polypropylene, Moplen HP 456J (Basell Orlen Polyolefins, Poland); and mineral filler: Sillikolloid P87 (Hoffman Mineral GmbH, Germany) have been used for composite preparation.
Sillikolloid $\quad \mathrm{P} 87-\mathrm{SiO}_{2}-\mathrm{Al}_{2}\left[(\mathrm{OH})_{4} \mathrm{Si}_{2} \mathrm{O}_{5}\right] \quad$ (or $\left.\mathrm{Al}_{2} \mathrm{O}_{3} \cdot 2 \mathrm{SiO}_{2} \cdot 2 \mathrm{H}_{2} \mathrm{O}\right)$ mixture consists of $35 \mathrm{wt} \%$ of kaolin, $55 \mathrm{wt} \%$ of crystalline silica and $10 \mathrm{wt} \%$ of colloidal silica (density $2.6 \mathrm{~g} / \mathrm{cm}^{3}$, bulk density $0.25 \mathrm{~g} / \mathrm{cm}^{3}$, surface area (BET) $-12 \mathrm{~m}^{2} / \mathrm{g}$, particle size: approx. from 0.5 to $20 \mu \mathrm{m}$ ).

\subsection{Composite extrusion}

Polypropylene (i-PP) in granulated form was mixed with the filler by simple powdering and the mixture was subjected to further processing. The composites of i-PP containing 2.5, 5 and $10 \mathrm{wt} \%$ of the filler and neat polymer as a reference were prepared by extrusion in a co-rotating twinscrew lab extruder type Bühler BTSK 20/40D in the following conditions: extruder heating zones: 190, 195, 195, $190^{\circ} \mathrm{C}$, temperature of extrusion die head $-185^{\circ} \mathrm{C}$, screw speed $-300 \mathrm{~s}^{-1}$.

The obtained composites in pelletized form were then subjected to further "cast" extrusion to get the ribbon of $145 \mathrm{~mm} \times 0.145 \mathrm{~mm}$ using single-screw lab extruder PlastiCorder PLV 151 Brabender in the following conditions: extruder heating zones $-225,235,235^{\circ} \mathrm{C}$, temperature of extrusion die head $-245^{\circ} \mathrm{C}$, screw speed $-75 \mathrm{~s}^{-1}$.

The obtained composite films have a thickness of approximately $0.10 \pm 0.01 \mathrm{~mm}$.

\subsection{Analysis}

\subsubsection{Scanning electron microscopy (SEM)}

Scanning Electron Microscope LEO 1430 has been used to study the composite morphology. A secondary electron (SE) detector, enabling very fine detail to be resolved, was used. SEM pictures were made for both the surface and cross-section after brittle fracture of the samples in liquid nitrogen. Samples for SEM were sputtered with gold or imaged directly without coating. The most representative pictures are presented in this paper.

\subsubsection{Thermogravimetry (TGA)}

Thermogravimetric analysis was carried out using simultaneous thermal analyzer NETZSCH STA 449 F5 Jupiter ${ }^{\circledR}$ (NETZSCH-Gerätebau $\mathrm{GmbH}$ ) in order to acquire DSCTGA data. All analyses were conducted in nitrogen atmosphere in the temperature range from room temperature (RT) to $650^{\circ} \mathrm{C}$. The heating rate and the gas flow rate were $10^{\circ} \mathrm{C} \mathrm{min}^{-1}$ and $100 \mathrm{~mL} \mathrm{~min}{ }^{-1}$, respectively. The mass of the samples was about $5 \mathrm{mg}$.

The following parameters have been determined: temperature of decomposition onset $\left(\mathrm{T}_{\mathrm{o}}\right)$, temperature at maximum rate of the process $\left(\mathrm{T}_{\max }\right)$, temperature of degradation 
end $\left(\mathrm{T}_{\text {end }}\right)$, weight loss $(\Delta \mathrm{m})$, heat of exo/endothermic transition and corresponding temperatures.

Proteus Thermal Analysis (Version 6.1.0) software has been used for results elaboration.

\subsubsection{X-Ray diffraction $(X R D)$}

X-ray diffraction experiments were carried out with a X'PERT Pro Philips Diffractometer $\left(\mathrm{Cu} K_{\alpha} 1\right.$, wavelength $1.54056 \AA$, range $2 \theta 5^{\circ}-90^{\circ}$, scan step size $0.020^{\circ}$, time per step $3.00 \mathrm{~s})$. The degree of polymer crystallinity $\left(\mathrm{X}_{\mathrm{c}}, \%\right)$ has been determined using a two-phase model, i.e., assuming that the sample is composed of crystals and amorphous regions with no semi-crystalline (mesomorphic) phases:

$X_{c}=\frac{A_{c r}}{A_{c r}+A_{a m}} 100 \%$

where, $\mathrm{A}_{\mathrm{cr}}$ and $\mathrm{A}_{\mathrm{am}}$ are areas of signals of crystalline and amorphous phases, respectively.

The area of the signals from the mineral filler has been subtracted from the total area under the XRD curve of composites. The mathematical distribution of the complex pattern into components has been done using Voigt function to get the best fit to the real XRD shape.

\subsubsection{Mechanical properties}

The study of the mechanical properties was performed using a tensile testing machine type TIRAtest 27,025 at standard conditions (room temperature). The strength of the measuring head was $3 \mathrm{kN}$, feed speed of crosshead: $\mathrm{V}_{1}=1.0 \mathrm{~mm} \mathrm{m^{-1 }}$ and $\mathrm{V}_{2}=100.0 \mathrm{~mm} \mathrm{~min}^{-1}$. Dimensions of the samples: the length of the measurement section $1_{0}=50 \mathrm{~mm}$; and the width of the sample $\mathrm{a}=15 \mathrm{~mm}$.

The following parameters have been determined: tensile stress at break $\left(\sigma_{\mathrm{b}}, \mathrm{MPa}\right)$, maximum stress i.e. ultimate strength $\left(\sigma_{\mathrm{m}} \mathrm{MPa}\right)$, elongation at break $\left(\varepsilon_{\mathrm{b}}, \%\right)$, elongation at maximum stress $\left(\varepsilon_{\mathrm{m}}, \%\right)$. Elasticity, Young's modulus $\left(\mathrm{E}_{\mathrm{t}}, \mathrm{MPa}\right)$ and limit of the material elasticity have been specified from the straight part of stress-strain relationship registered at low stretching rate. All results are the average of at least 6 measurements.

\subsubsection{Piezoelectric properties}

To manufacture the electrets, the films were polarized at constant electric field $100 \mathrm{~V} \mathrm{\mu m}^{-1}$, in a climatic chamber (VMT Heraeus-Vötsch). The samples were placed between two metal contact electrodes and then heated up to $85^{\circ} \mathrm{C}$. After reaching the upper temperature the voltage was switched on, and voltage value gradually increased. The polarization time was $1 \mathrm{~h}$. The sample was then cooled down to room temperature and the voltage was switched off. The electric field and the temperature were selected for film basing on its breakdown voltage $>150 \mathrm{~V} \mathrm{\mu m}^{-1}$ at $80^{\circ} \mathrm{C}$. The voltage and charge have been measured every few days for 55 days using contact electrodes with surface of $10 \mathrm{~cm}^{2}$. Then the same samples were aged at $60^{\circ} \mathrm{C}$ for half an hour and next electrical signal were checked again several times (during 55-120 days after polarization).

The density of the piezoelectric charge is proportional to stress and the piezoelectric constant $d_{33}$ is the coefficient of proportionality.

$\frac{Q}{A}=d_{33} P$

where, $\mathrm{Q}$ is the generated charge, $\mathrm{A}$ is the surface of the electrode, $P$ is the stress and $d_{33}$ is the piezoelectric charge coefficient.

From the above equation, taking into account the definition of the stress, we get:

$d_{33}=\frac{Q}{F}$

where, $\mathrm{F}$ is the force acting on the electrets.

\section{Results and discussion}

\subsection{General remarks concerning the prepared composites}

Isotactic PP was chosen for these studies owing to the presence of crystalline phase because films made of crystalline polymer exhibit often piezoelectric effect.

The filler, which is a mixture of crystalline and amorphous silica with lamellar kaolinite, is a valuable raw material applied in plastic industry, as it can be well dispersed in a polymer matrix and can improve rheological properties of polymers. Selected filler has been added to polypropylene in amount of $2.5-10 \%$. Such mixtures were extruded to obtain films.

Mixing the components and preparation of the composites under the conditions described above has not caused any technical problems. The obtained samples were produced in the form of opaque cream-colored strips.

From the point of view of practical applications in microelectronics, it is important to know the thermal and mechanical properties of these polymeric composites designed for microelectronics, whereas the crystallinity and morphology determine the possibility of accumulation of electric charge, which allow us to obtain the piezoelectric effect. 
Fig. 1 SEM images of the composite components: i-PP - surface of extruded film (a), i-PP - cross-section (b) and filler powder (Sillikolloid P87) (c)

\subsection{Morphology studies by SEM}

SEM images of the composite components are shown in Fig. 1. Pure i-PP (in the form of extruded strip) does not show any specific details of the structure which is relatively smooth and uniform, even at high magnification (Fig. 1a). Also the cross-section of the i-PP does not show any peculiarities (Fig. 1b). In this picture one can see traces of pulling the sample. Despite freezing in liquid nitrogen, the sample is still ductile and there is no completely brittle fracture. The PP sample is relatively homogeneous.

An image of the filler powder shows mainly irregular grains, the size of micrometers, and also slightly less elongated lamellar structures and flat sheets (Fig. 1c).

SEM images of the composites with the filler show the presence of mineral microparticles dispersed in the polymer matrix (Fig. 2). Most of the microparticles has more or less regular spherical shape. They are visible both on the surface (Fig. 2a, c, e) and in the bulk of the samples as can be observed on the cross-section images after the brittle fracture (Fig. 2b, d, f).

With increasing content of the incorporated modifier, more filler particles having similar sizes were observed. Besides the grains of the filler, also the layers or elongated lamellae could be seen at higher magnification (Fig. 3b, c). Moreover, voids, particularly clearly visible in crosssections (Fig. 3), are the important element of the internal structure of the composites. These holes of different shapes and sizes are sometimes filled with modifier particles. Such voids are usually responsible for the accumulation of piezoelectric charge in the polymeric materials $[5-9,11]$. In most cases, a lack of wettability and adhesion is observed, which is caused by immiscibility of components.

The lack of adhesion between the filler and the polymer can be explained by different chemical nature and structure of the composite constituents. PP is a hydrophobic polymer, build of isotactic sequences typical of regular arrangement of polymer chains. The physical properties of the filler are completely different. Although the composition of elements in kaolinite is well known, its structure is quite complex [12]. This mineral, appearing in triclinic system, creates a layered silicate, wherein the silica tetrahedra are associated with alumina octahedra through oxygen atoms. $\mathrm{Si}$ is surrounded by four oxygen atoms, while $\mathrm{Al}$ is coordinated by six other oxygen atoms (two $\mathrm{O}$ from silica and four from $\mathrm{OH}$ groups). Parallel pseudohexagonal plates, more or less regularly arranged, are linked by the intermolecular interactions between them.
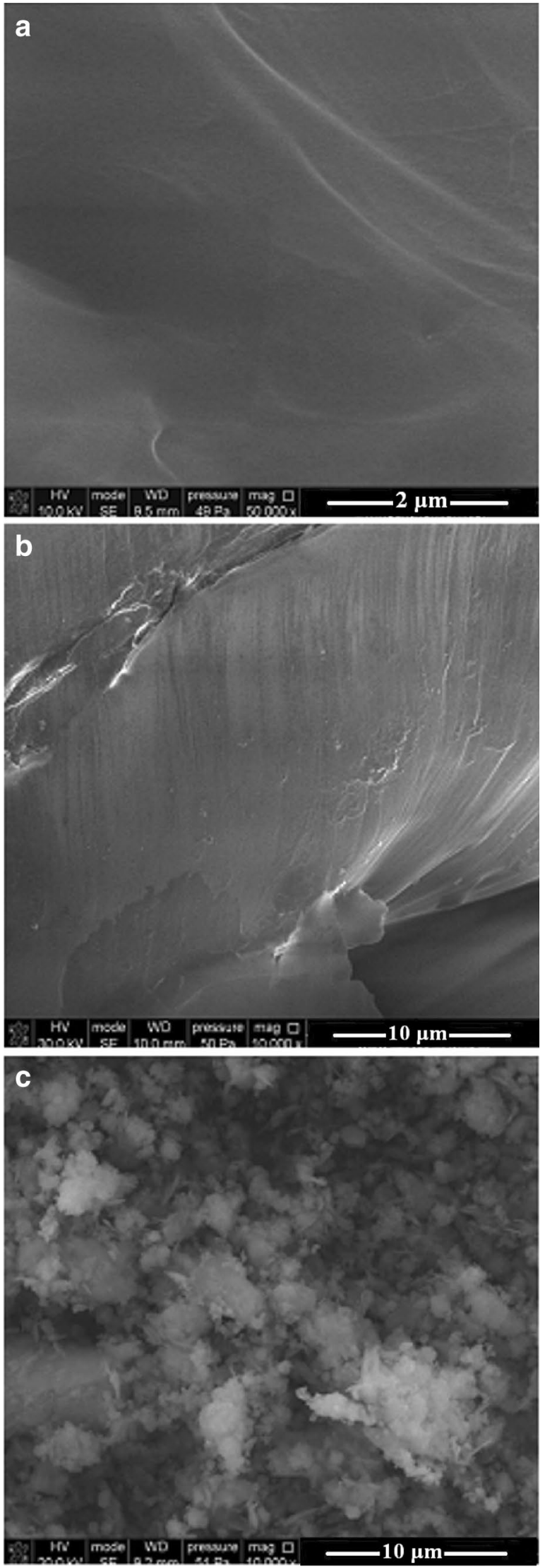
Fig. 2 SEM images of i-PP composites containing $2.5 \%$ (a, b), $5 \%(\mathbf{c}, \mathbf{d})$ and $10 \%(\mathbf{e}, \mathbf{f})$ of filler. Surface images: a, c, e; cross-sections of the samples broken in liquid nitrogen: $\mathbf{b}, \mathbf{d}$, f. Magnification $\times 10,000$
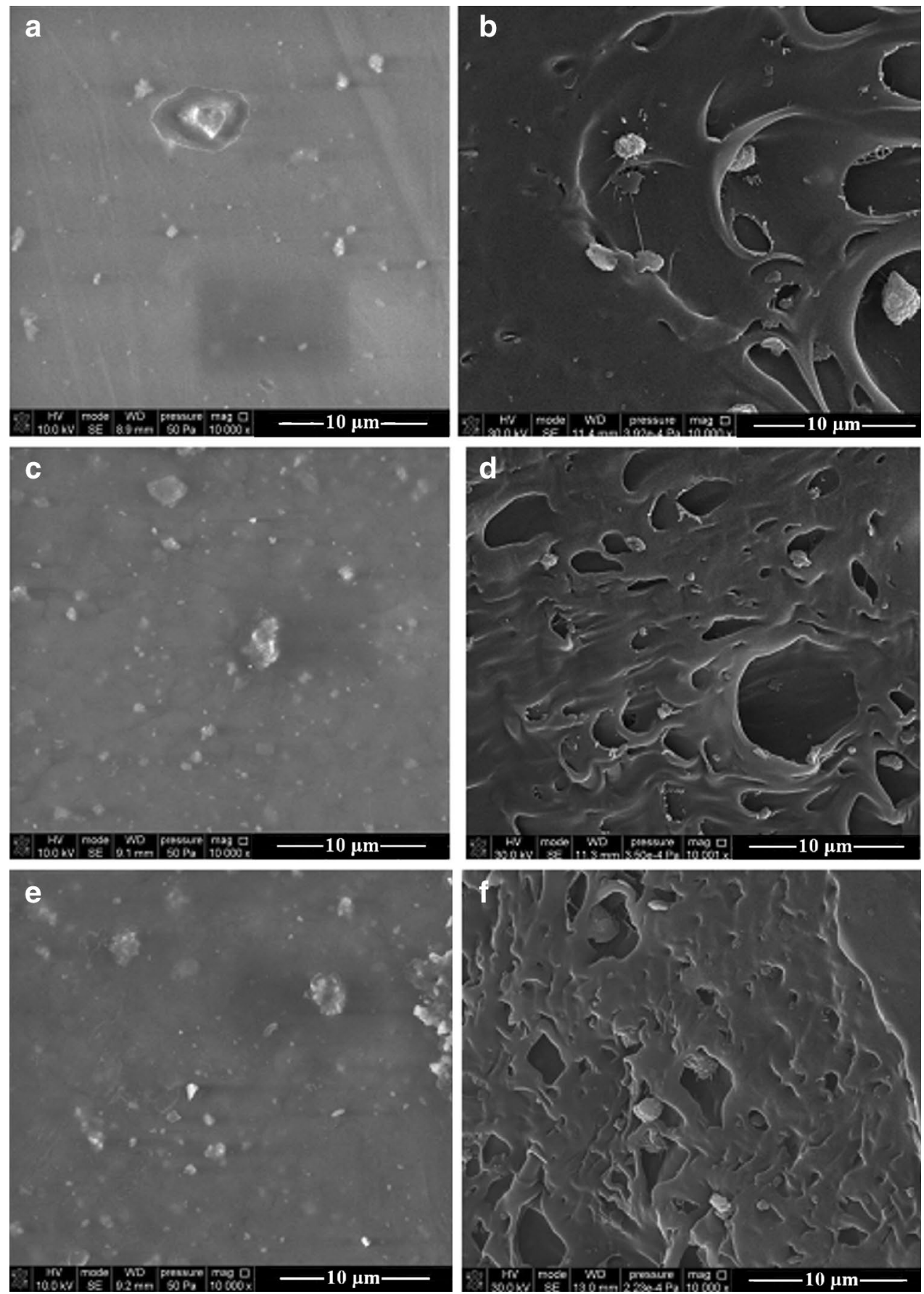

Although both kaolinite and silica are electrically neutral, they contain polar covalent bonds: Si-O and Al-O. The difference in electronegativity between $\mathrm{Si}$ and $\mathrm{O}$ is 1.7 and it is somewhat higher than between $\mathrm{Al}$ and $\mathrm{O}-1.9$, which indicates that Al-O bond has less covalent nature than Si-O, which is confirmed by $a b$ initio calculation [13]. Taking into account the presence of crystallization water in the silicate, it can be concluded that the filler is much more polar compared to PP. It should be also added that in the production of the composite materials no compatibilizer was used.
The lack of affinity and adhesion between PP and the filler results in the absence of intercalation of the filler particles by macromolecules. Thus, intercrystalline regions are not formed. However, mineral inclusions are partially anchored in the PP matrix (the connections between the filler particles and the polymer are shown in the SEM images, e.g. in Fig. $3 b, c)$ as a result of the simultaneous action of shear forces and elevated temperature during processing. It can therefore be postulated the formation of a specific core structure inside the cavities filled with particles of modifier. 

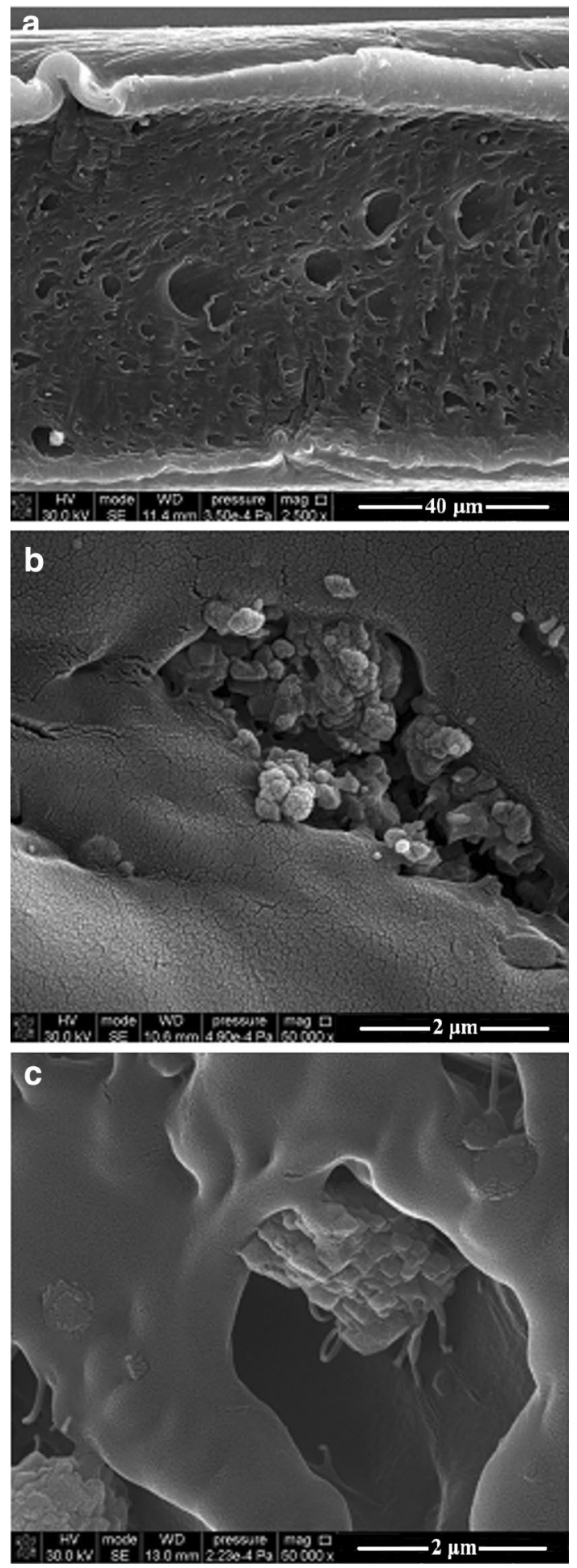

Fig. 3 The details of i-PP composite structure. SEM images (crosssections) at different magnification

\subsection{Thermogravimetric analysis (TGA)}

The neat polymer, the filler and the composites of different compositions were analyzed by thermogravimetric analysis in order to determine their thermal stability. Figure 4 shows TGA results for i-PP and the filler (Sillicolloid P87).

PP is stable up to about $360^{\circ} \mathrm{C}$, the one-step degradation occurs in the range of $360-460^{\circ} \mathrm{C}$ with maximal rate at $452{ }^{\circ} \mathrm{C}$. The polymer decomposition is complete $(100 \%)$ at $500^{\circ} \mathrm{C}$ in nitrogen atmosphere (Fig. 4a). First endothermic peak on DSC curve at $167^{\circ} \mathrm{C}$ (and corresponding $\Delta \mathrm{H}=73 \mathrm{~J} / \mathrm{g}$ ) is attributed to melting crystalline phase. Two next extrema: exothermic peak at $380{ }^{\circ} \mathrm{C}$ and endothermic one at $484^{\circ} \mathrm{C}$ are directly connected with sample decomposition and emission of degradation products. The detailed mechanism and kinetics of thermal degradation of the i-PP had been previously discussed in the literature [14-18]. The volatile products of PP decomposition in inert atmosphere are alkanes, alkenes, dienes and even small amount of aromatic compounds. This indicates that random main chain scission may be accompanied by intermolecular transfer of hydrogen atoms or radicals and rearrangement reactions. As previous kinetic studies have shown, the order of decomposition rate of PP is 0.35 , and the apparent activation energy is in the range of $129-139 \mathrm{~kJ} / \mathrm{mol}$, dependently on the heating rate [18]. Our results obtained from thermal analysis of i-PP are consistent with those published earlier for this polymer $[18,19]$.

As expected, the filler appeared to be very stable up to $600^{\circ} \mathrm{C}$ under applied conditions (Fig. 4b). Only slight weight loss $(3.6 \%)$ has been observed at higher temperatures (above $400^{\circ} \mathrm{C}$ ) probably due to the impurities decay. This filler is characterized by continuous heat evolution in the whole temperature range.

The results of TGA analysis for i-PP composites containing 2.5, 5 and $10 \%$ of the filler are shown in Fig. 5. It can be seen that TG curves move towards higher temperatures with increasing filler content in the sample (Fig. 5a), indicating an improvement in thermal stability of the composites with respect to pure i-PP. The parameters acquired from the above curves, illustrating the heat resistance of the studied systems, are summarized in Table 1. A rise in temperature of decomposition onset $\left(\mathrm{T}_{\mathrm{o}}\right)$ is from 20 to over $50^{\circ} \mathrm{C}$. Much smaller changes have been observed for the temperature at the maximum rate of decomposition. The process ends at approximately the same temperature for all studied samples.

DTG curves show that the rate of thermal degradation is much higher for the composites than for neat i-PP (Fig. 5b). Incomplete weight loss for the composites is due to the inorganic residue that remained after polymer decomposition.

DSC curves of all composites show endothermic peak similar to neat i-PP (Fig. 4a) due to the melting crystalline phase. Position of the melting peak is almost the same for all samples. Also the heats of fusion calculated from the peak area for $\mathrm{i}-\mathrm{PP}+$ filler are similar to the value for neat 
Fig. 4 TG, DTG and DSC curves of i-PP (a) and Sillikolloid P87 filler (b)
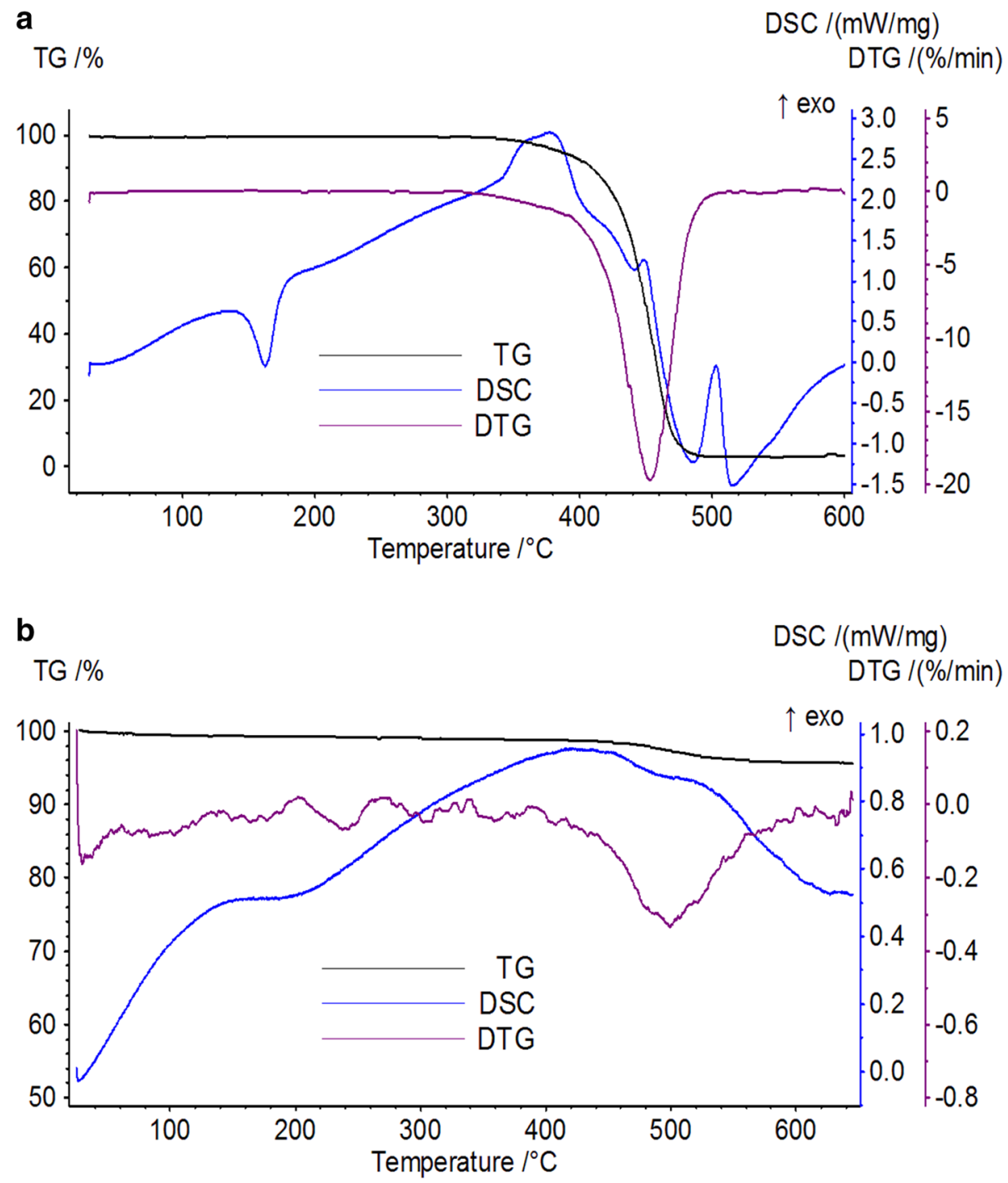

polymer. Degradation of the polymer is also endothermic process preceded by an exothermic one. Minimum of DSC peak in the temperature range $400-480^{\circ} \mathrm{C}$ occurs at similar or slightly lower temperature for all samples, but $\Delta \mathrm{H}$ of decomposition increases considerably (even several times) for the composites compared to i-PP. It means that more heat is needed to decompose the composites than unmodified polymer. The exothermic process (occurring just before the rapid main weight loss) can be attributed to the polymer oxidation. The analyses were conducted in nitrogen atmosphere, but the observed oxidation may be caused by the adsorbed oxygen which could have been incorporated into the polymer bulk during extrusion taking place in air. Such course of thermal degradation of PP corresponds well to the results reported by Golebiewski and Galeski [20]. Thus, our observations are similar to that of the mentioned authors. We also noticed the decrease in exothermic effect in the samples with increasing content of the filler, which may be related to the reduced oxygen diffusion in the polymer composites (i.e. more difficult oxygen penetration through the composite).

\subsection{XRD analysis}

The crystallinity of the i-PP in the composites with the filler was analyzed by XRD. Polymer showed typical of semicrystalline phase XRD pattern (Fig. 6) with signals at $2 \Theta: 14.16^{\circ}, 17.01^{\circ}, 18.65^{\circ}, 21.30 / 21.88^{\circ}$ and $25.59^{\circ}$ corresponding to (110), (040), (130) and (111)/(131) and (060) planes, respectively. These reflections are present in the studied composites too (Fig. 7). The observed shape of diffraction profile can be attributed to the $\alpha$-structure of i-PP $[21,22]$. The calculated degree of crystallinity of this polymer is about $55 \%$. This value is within the range of the values previously established for the i-PP. It is well known that the degree of crystallinity depends on the annealing time 
Fig. 5 TG (a) and DTG (b) curves of i-PP composites a

TG $1 \%$

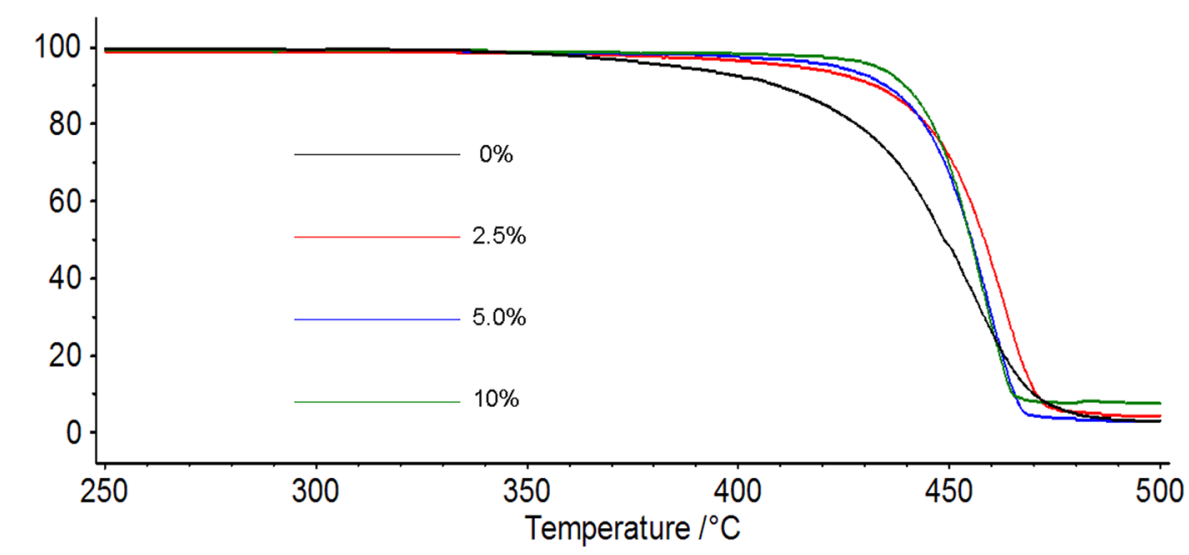

b

DTG /(\%/min)

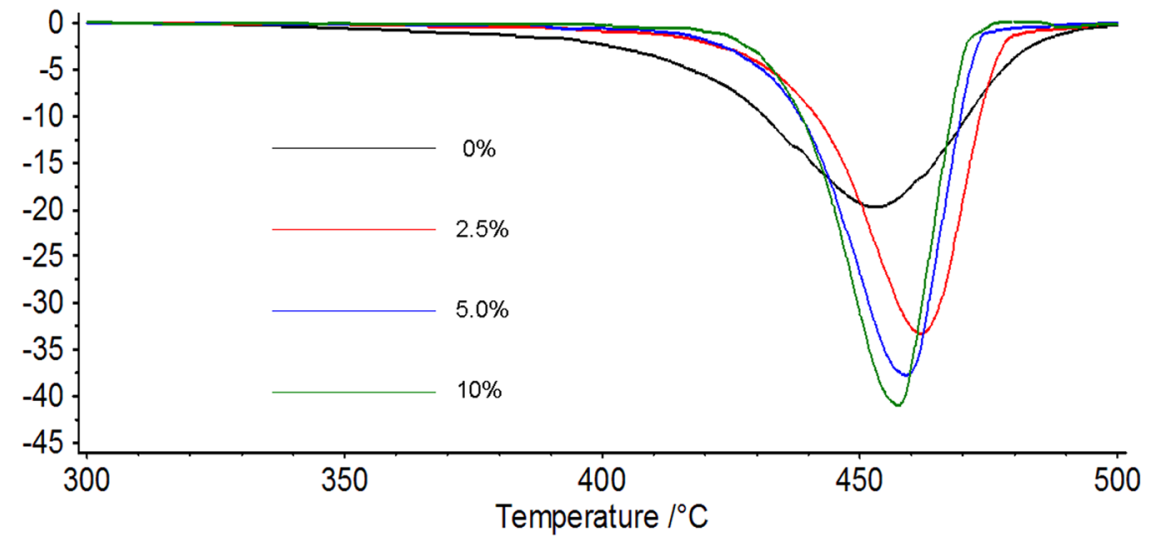

Table 1 Thermal parameters determined from TGA analysis for i-PP, silicate filler (Sillikolloid P87) and i-PP+ filler composites

\begin{tabular}{|c|c|c|c|c|c|c|}
\hline Sample & $\mathrm{T}_{\mathrm{o}}\left({ }^{\circ} \mathrm{C}\right)$ & $\mathrm{T}_{\max }\left({ }^{\circ} \mathrm{C}\right)$ & $\mathrm{T}_{\text {end }}\left({ }^{\circ} \mathrm{C}\right)$ & $\Delta \mathrm{m}(\%)$ & $\begin{array}{l}\text { Melting } \\
\mathrm{T}_{\text {Endo }}\left({ }^{\circ} \mathrm{C}\right) / \Delta \mathrm{H}\left(\mathrm{J} \mathrm{g}^{-1}\right)\end{array}$ & $\begin{array}{l}\text { Decomposition } \\
\mathrm{T}_{\text {Endo }}\left({ }^{\circ} \mathrm{C}\right) / \Delta \mathrm{H}\left(\mathrm{J} \mathrm{g}^{-1}\right)\end{array}$ \\
\hline i-PP & 360 & 452 & 467 & 100 & $167 / 73$ & $\begin{array}{l}484 / 134 \\
(450-500)^{*}\end{array}$ \\
\hline $\mathrm{i}-\mathrm{PP}+2.5 \%$ filler & 380 & 462 & 471 & 94.5 & $165 / 58$ & $\begin{array}{l}485 / 749 \\
(450-550)\end{array}$ \\
\hline $\mathrm{i}-\mathrm{PP}+5 \%$ filler & 400 & 459 & 466 & 96.1 & $165 / 72$ & $\begin{array}{l}478 / 327 \\
(420-496)\end{array}$ \\
\hline i-PP $+10 \%$ filler & 415 & 457 & 464 & 91.5 & $164 / 66$ & $\begin{array}{l}465 / 321 \\
(430-490)\end{array}$ \\
\hline Silicate filler & $\sim 400$ & 512 & $\sim 600$ & 3.6 & $\begin{array}{l}\text { Exo }-/ 1401 \\
(20-600)\end{array}$ & \\
\hline
\end{tabular}

*In brackets the temperature range of transition $\left(\right.$ in ${ }^{\circ} \mathrm{C}$ ) is given

and temperature, moreover, the macromolecules order in the bulk differs from the surface arrangement [21].

In XRD pattern of the filler, the main signal appears at $2 \Theta$ of $26.61^{\circ}$ (Fig. 6). In addition, several signals of lower intensity are detected at $12.33^{\circ}, 20.84^{\circ}, 24.91^{\circ}$ (and in the degree range of $30-80^{\circ}$, not shown here). This pattern confirms the presence of crystalline kaolinite and silica in the filler [23, 24].

Data from deconvoluted XRD curves for i-PP and the composites are collected in Table 2 . The data contain signal 
Fig. 6 XRD patterns of i-PP and the filler. Kaolin (K) and quartz $(\mathrm{Q})$ peaks are identified in filler pattern

Fig. 7 XRD patterns of i-PP composites ( $\mathrm{F}$ denotes signals of filler)
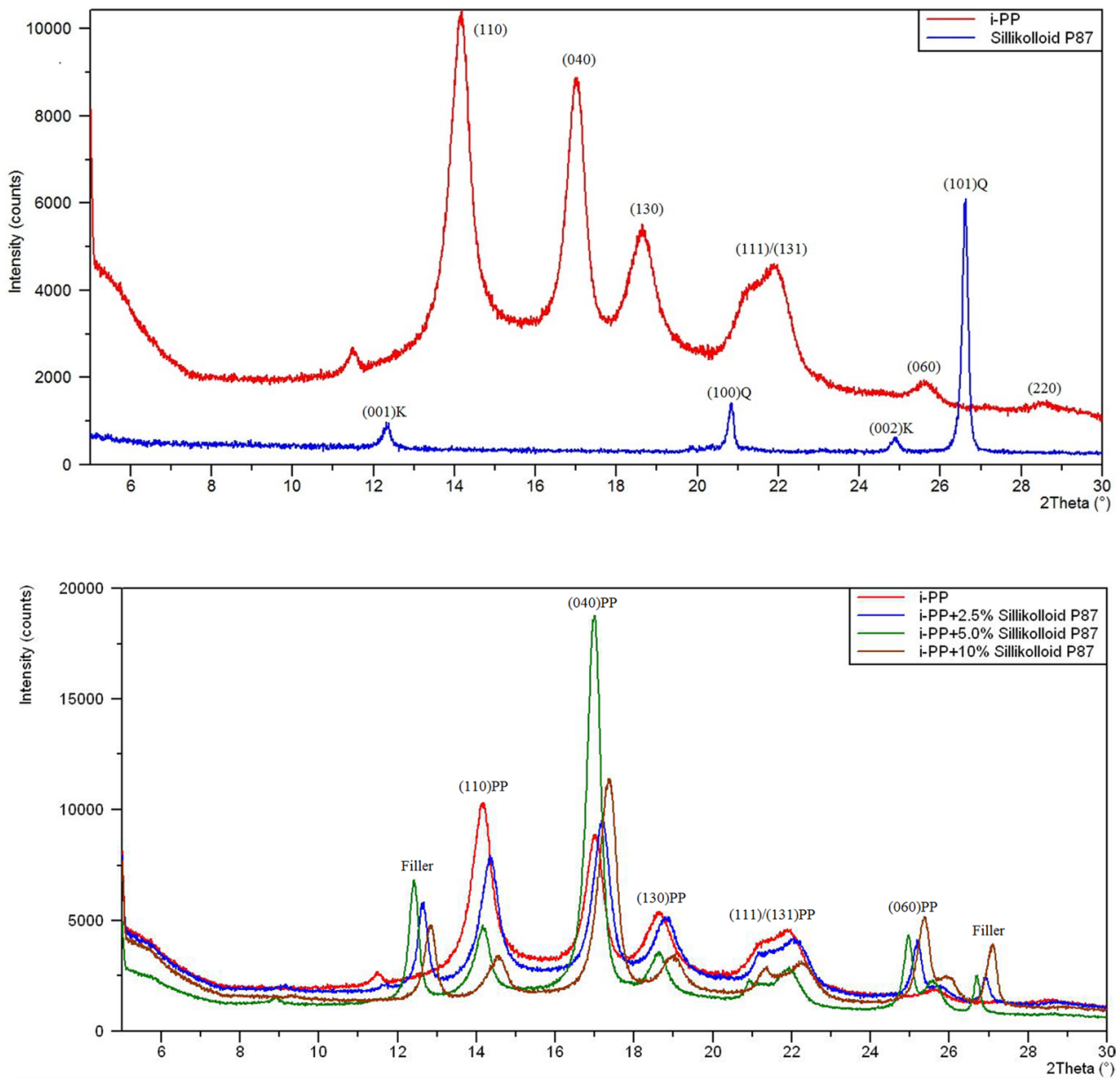

position, full width at half maximum, distance between planes of atoms (d-spacing) and degree of crystallinity.

PP composites filled with silica exhibit similar XRD profile to neat polymer; however, slight shifts of the signals and changes in their intensities have been observed (Fig. 7; Table 2). Additionally, peaks of the low intensity, characteristic of the filler, are also present in XRD patterns

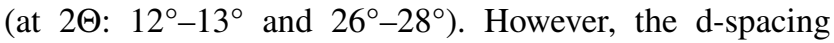
remains unchanged for the i-PP, indicating no alteration in the arrangement of the polymer chains during the modification process. That is, mainly the preparation conditions (temperature, time in molten state, cooling rate) influence the type of the structure order in polymer.

Interlayer spacing, practically unchanged, clearly indicates that the filler does not disturb PP crystallization and intercalation of macromolecules into the filler grains and sheets, which was seen from microscopic studies. This conclusion is consistent with that from DSC results, as it was also suggested that the crystalline structure of PP in the composites remained unchanged. XRD data obtained for the studied systems correspond to previously published results for other composites based on i-PP [25-27].
Interestingly, the introduction of the filler into PP causes an increase in degree of crystallinity of the polymer by approx. 6-15\%. It suggests that silica grains can act as nucleating agents, which is advantageous in the case of production of piezoelectric materials.

\subsection{Mechanical properties}

Stress-strain curves, obtained in a standard tensile test for i-PP and its composites, are typical of tough-hard plastics with necking region. Table 3 contains the results from mechanical tests of the studied samples.

As can be seen, for i-PP composites, Young's modulus systematically rises with increasing content of the filler in the sample. Similar effect was often observed for polymer nanocomposites with various types of silicone fillers, particularly at low content of fillers in a matrix [28, 29]. The increase in the Young's modulus indicates good quality of samples and lack of defects weakening the structure, which is not achieved easily in the case of the cellular structure. Voids in the polymer matrix generally worsen significantly the mechanical properties of composites. 
Table 2 Main signals in XRD patterns $\left(2 \Theta,^{\circ}\right)$, full width at half maximum $\left(\mathrm{FWHM},{ }^{\circ}\right)$, d-spacing $(\AA)$ and crystallinity degree $(\mathrm{X}, \%)$ in i-PP and its composites with silicate filler (Sillikolloid P87)

\begin{tabular}{|c|c|c|c|c|}
\hline Sample & $2 \Theta\left({ }^{\circ}\right)$ & FWHM $\left(^{\circ}\right)$ & d-spacing $(\AA)$ & $\mathrm{X}(\%)$ \\
\hline i-PP & $\begin{array}{l}14.1 \\
17.0 \\
18.6 \\
21.9\end{array}$ & $\begin{array}{l}0.58 \\
0.52 \\
0.81 \\
0.88\end{array}$ & $\begin{array}{l}6.3 \\
5.2 \\
4.6 \\
4.0\end{array}$ & 55.0 \\
\hline $\mathrm{i}-\mathrm{PP}+2.5 \%$ filler & $\begin{array}{l}12.6^{*} \\
22.1^{*} \\
14.3 \\
17.1 \\
18.8 \\
22.1\end{array}$ & $\begin{array}{l}0.28^{*} \\
0.28^{*} \\
0.55 \\
0.50 \\
0.75 \\
0.82\end{array}$ & $\begin{array}{l}7.0^{*} \\
4.2^{*} \\
6.2 \\
5.2 \\
4.7 \\
4.0\end{array}$ & 61.2 \\
\hline $\mathrm{i}-\mathrm{PP}+5 \%$ filler & $\begin{array}{l}12.4^{*} \\
20.9^{*} \\
14.2 \\
17.0 \\
18.6 \\
21.9\end{array}$ & $\begin{array}{l}0.26^{*} \\
0.26^{*} \\
0.48 \\
0.39 \\
0.51 \\
0.62\end{array}$ & $\begin{array}{l}7.1^{*} \\
4.2^{*} \\
6.3 \\
5.2 \\
4.8 \\
4.1\end{array}$ & 66.5 \\
\hline i-PP $+10 \%$ filler & $\begin{array}{l}12.8^{*} \\
21.3^{*} \\
14.5 \\
17.3 \\
19.0 \\
22.3\end{array}$ & $\begin{array}{l}0.31^{*} \\
0.46^{*} \\
0.57 \\
0.49 \\
0.62 \\
0.68\end{array}$ & $\begin{array}{l}6.9^{*} \\
4.2^{*} \\
6.1 \\
5.1 \\
4.7 \\
4.0\end{array}$ & 70.7 \\
\hline
\end{tabular}

*Signals from filler

The elasticity range, in which Hooke's law is fulfilled, extends to the stress values of $23-26 \mathrm{MPa}$, which is sufficient for the piezoelectric application of the materials. Interestingly, the upper limit of elasticity increases slightly in the presence of the filler in i-PP composites.

Nevertheless, other estimated mechanical parameters depend on quantitative composition of the sample. The lowest content $(2.5 \%)$ of the filler in the composite can lead to slight improvement in $\sigma_{\mathrm{b}}, \sigma_{\mathrm{m}}$, and $\varepsilon_{\mathrm{b}}$ (while $\varepsilon_{\mathrm{m}}$ decreases), contrary to the composites of i-PP containing 5 and $10 \%$ of the filler. However, the observed changes in mechanical properties are not so extensive (except for $\varepsilon_{\mathrm{m}}$ ). It should be emphasized that in the case of composites used as piezoelectric materials, the most important is the resistance to repetitive relatively small mechanical forces. Moreover, the materials should be characterized by reversible deformation in the initial range of stresses.
The improvement in mechanical properties (Young modulus and the limit of elasticity) can be related to the increase in the degree of crystallinity and more dense macromolecules packing, despite the heterogeneity of the composites. One may also find that the dispersion of the filler particles of different sizes and the distribution of voids are good enough to acquire adequate mechanical properties for the intended uses.

\subsection{Piezoelectrical properties}

It is difficult to predict the piezoelectric properties of crystalline polymers doped with mineral fillers on the base of temporary knowledge concerning the piezoelectric materials. It is well known that the inorganic particles introduced into polymer bulk are the source of charge carriers and together with the structural defects can positively influence the electrets formation. It is important that their trapping energy should be large enough to form a stable system. On the other hand, too many structural defects (e.g. voids) may result in poor mechanical properties. Thus, the best composition of the composites with desired properties should be a kind of compromise. Therefore, the piezoelectric charge and voltage of new composites have to be measured, which allows to predict the potential usefulness of the studied materials.

The plot of piezoelectric charge density and voltage (measured at press of $100 \mathrm{kPa}$ ) as a function of time is presented in Fig. 8. One can see that the charge density value determined after several days decreases systematically in time for neat i-PP. For the composites, the charge values vary only slightly and these changes enhance or decrease depending on the charge obtained during polarization process. Such alterations may be related to uneven charge distribution on the electret's surface. The same dependence has been found for sample voltage investigated in time.

The dependence of the electric charge vs. mechanical stress acting on the sample, determined after 115 days from polarization procedure, was used for calculation of $d_{33}$ constant (Fig. 9). For comparative purposes, the values for PVDF film (as a reference) have been presented in Fig. 9. As can be seen, $d_{33}$ constant is bigger for composites than for PVDF film. It reaches $40 \mathrm{pC} / \mathrm{N}$ for lower stress and falls
Table 3 Mechanical properties of i-PP and its composites with silicate filler (Sillikolloid P87)

\begin{tabular}{lllllll}
\hline Sample & $\sigma_{\mathrm{m}}(\mathrm{MPa})$ & $\sigma_{\mathrm{b}}(\mathrm{MPa})$ & $\varepsilon_{\mathrm{m}}(\%)$ & $\varepsilon_{\mathrm{b}}(\%)$ & $\mathrm{E}_{\mathrm{t}}(\mathrm{MPa})$ & $\begin{array}{l}\text { The limit } \\
\text { of elasticity } \\
(\mathrm{MPa})\end{array}$ \\
\hline i-PP & 30.5 & 30.1 & 511 & 626 & 1064 & 23.2 \\
i-PP+ 2.5\% filler & 31.0 & 30.5 & 274 & 644 & 1068 & 25.0 \\
i-PP+5\% filler & 30.1 & 26.3 & 268 & 617 & 1142 & 25.5 \\
i-PP+ 10\% filler & 28.5 & 25.8 & 5.4 & 543 & 1259 & 26.5 \\
\hline
\end{tabular}


Fig. 8 Dependence of piezoelectric charge density and voltage as a function of time (filled markers points represent measurements made after aging of samples)
Fig. 9 Dependence of piezoelectric constant as a function of pressure
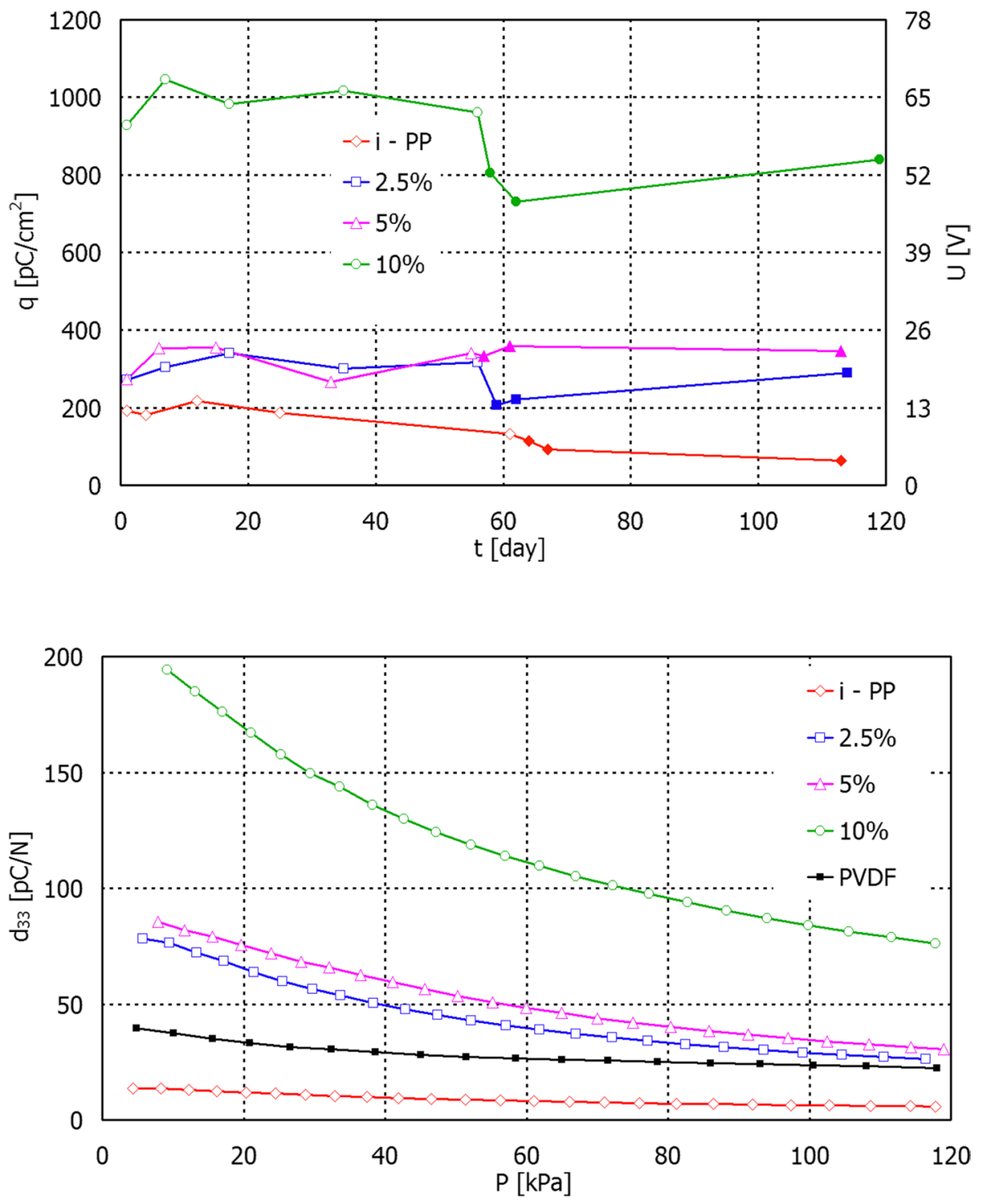

to $23 \mathrm{pC} / \mathrm{N}$ for higher stress. These results are consistent with reference data [30]. For composite with $10 \%$ of the filler, $\mathrm{d}_{33}$ is several times higher than for PVDF film. For low stresses, it reaches $200 \mathrm{pC} / \mathrm{N}$, for higher ones, it is ca. $\sim 80 \mathrm{pC} / \mathrm{N}$.

The studies concerning possibility of obtaining composites, based on PP, having high piezoelectric constants were suggested earlier by other authors [31, 32]. The obtained value of $\mathrm{d}_{33}$ was several times smaller than that for PP after double expansion process [3, 4]. However, these films were characterized by low values of Young's moduli, which made their possible applications limited to the devices in which small stress values of materials could be sufficient (microphones, loudspeakers).
In this work, the piezoelectric PP composites with the filler had higher $\mathrm{d}_{33}$ values, also Young's modulus for these composites slightly increased compared to neat i-PP and was in the range from 1068 to $1259 \mathrm{MPa}$ (Table 3). This can be caused by the formation of skeletal structure inside voids (Fig. 3c), as discussed in Sect. 3.2. In the presence of such voids, depolarization process of electrets was slower because of stronger charge trapping and also piezoelectric properties were enhanced by specific structure of cavities (Fig. 8). Moreover, high values of Young's modulus of these composites is an advantage because they can have many practical applications.

It is important that the measured piezoelectric charge was stable, despite slight alterations during storage for 115 days. Also aging of the samples at $65^{\circ} \mathrm{C}$ for $0.5 \mathrm{~h}$ did not cause a significant change in the voltage and the 
piezoelectric charge, which is very promising outcome from practical point of view.

\section{Conclusion}

The i-PP composites containing silica based mineral filler - Sillikolloid P87, obtained in extrusion process, exhibited heterogeneous cellular morphology, confirmed by SEM. The good distribution of the filler in polymer matrix resulted in a growth in Young's modulus of the composites. The limit of elasticity of the composites appeared at stress of about 25-26 MPa. Other parameters from mechanical tensile tests (determined at break) worsened in composites but they are not very important in the case of piezoelectric materials working generally at low forces.

Large deformation of electrically charged voids under the influence of mechanical stress are possible because of good elastic properties of the films, which enables the achievement of high piezoelectric constants. For film made of neat PP, $\mathrm{d}_{33}$ constant reaches $\sim 14 \mathrm{pC} / \mathrm{N}$; for composite films of cellular structure, these values are much higher in the whole range of investigated stresses from 10 to $120 \mathrm{kPa}$. The highest $d_{33}$ value was obtained for PP film with $10 \%$ of the filler and reached $200 \mathrm{pC} / \mathrm{N}$ for lower stresses and $80 \mathrm{pC} / \mathrm{N}$ for higher ones. These values are much higher than that for neat PVDF film.

Isotactic PP is resistant to heat. Moreover, the introduction of the silica modifier to this polymer further improves its thermal stability. It can be concluded that the thermal stability of the studied systems is good enough to apply conventional processing methods as extrusion and to disperse properly the mineral filler in the polymer matrix in a molten state.

Summarizing, isotactic PP modified with the silicate filler (Sillikolloid P87) exhibited better piezoelectrical properties than neat i-PP, which was caused by altered morphology of the samples and higher degree of crystallinity. Inorganic mineral particles introduced into the polymer acted as nucleating agents and they were also the source of the structural defects. In these composites, the voids, well distributed in i-PP matrix, were the places where the piezoelectrical charge accumulated. Materials having such structure are characterized by high values of piezoelectric constants and good thermal stability.

One can expect that such types of i-PP composites may be raw piezoelectric materials for the production of sensors and micromachines in the nearest future.

Acknowledgement The project has been sponsored by National Science Centre (Poland) - DEC-2015/17/B/ST8/03396 from Nov. 20,
2015. The authors thank Mr Andrzej Cichocki (ITE, Kraków) for the measurements of piezoelectric properties.

Funding The funding was provided by Narodowe Centrum Nauki (Grant No. DEC-2015/17/B/ST8/03396).

Open Access This article is distributed under the terms of the Creative Commons Attribution 4.0 International License (http:// creativecommons.org/licenses/by/4.0/), which permits unrestricted use, distribution, and reproduction in any medium, provided you give appropriate credit to the original author(s) and the source, provide a link to the Creative Commons license, and indicate if changes were made.

\section{References}

1. C. Baur, D.J. Apo, D. Maurya, S. Priya, W. Voit, Advances in piezoelectric polymer composites for vibrational energy harvesting, chap. 1, in: polymer composites for energy harvesting, conversion, and storage. ACS Symp. Ser. 1161, 1-27 (2014)

2. A. Mellinger, F.C. Gonzalez, R. Gerhard-Multhaupt. Appl. Phys. Lett. 82, 254-256 (2003)

3. X. Zhang, J. Hillenbrand, G.M. Sessler, Appl. Phys. Lett. 85, $1226-1228$ (2004)

4. X. Zhang, G.M. Sessler, J. Hillenbrand, J. Electrostat. 65, 94-100 (2007)

5. M. Tang, Z. An, Z. Xia, X. Zhang, J. Electrostat. 5, 203-208 (2007)

6. A. Qaiss, H. Saidi, O. Fassi-Fehri, M. Bousmina. Polym. Eng. Sci. 52, 2637-2644 (2012)

7. Z. An, M. Mao, J. Cang, Y. Zhang, F. Zheng, J. Appl. Phys. 111, 024111 (2012)

8. H. Gilbert-Tremblay, F. Mighri, D. Rodrigue, J. Cell. Plast. 48, 341-354 (2012)

9. F. Mohebbi, A. Mighri, D. AJjji, Rodrigue, Adv. Polym. Tech. (2016). doi:10.1002/adv.21686

10. E. Klimiec, B. Królikowski, M. Machnik, W. Zaraska, J. Dzwonkowski, J. Electron. Mater. 44, 2283-2291(2015)

11. M. Paajanen, M. Wegener, R. Gerhard-Multhaupt, J. Phys. D 34, 2482-2488 (2001)

12. M. Bellotto, A. Gualtieri, G. Artioli, S.M. Clark, Phys. Chem. Miner. 22, 207-214 (1995)

13. R. Vuilleumier, N. Sator, B. Guillot, J. Non-Cryst. Sol. 357, 2555-2561 (2011)

14. H.W. Wong, L.J. Broadbelt, Ind. Eng. Chem. Res. 40, 4716$4723(2001)$

15. T.M. Kruse, H.W. Wong, L.J. Broadbelt, Macromolecules 36, 9594-9607 (2003)

16. J. Zhu, H. Gu, S.B. Rapole, Z. Luo, S. Pallvkar, N. Haldolaarachchige, T.J. Benson, T.C. Ho, J. Hopper, D.P. Young, S. Wei, Z. Guo, RSC Adv. 2, 4844-4856 (2012)

17. J. Gersten, V. Fainberg, G. Hetsroni, Y. Shindler, Fuel 79, 1679$1686(2000)$

18. Z. Gao, T. Kaneko, I. Amasaki, M. Nakada, Polym. Degrad. Stab. 80, 269-274 (2003)

19. M. Canetti, F. Betini, A. De Chirico, G. Audisio, Polym. Degrad. Stab. 91, 494-498 (2006)

20. J. Golebiewski, A. Galeski, Compos. Sci. Technol. 67, 34423447 (2007)

21. T. Nishino, T. Matsumoto, K. Nakame, Polym. Eng. Sci. 40, 336-343 (2000)

22. M. Favaro, M.C. Branciforti, R.E.S. Bretas, Mater. Res. 12, 454464 (2009) 
23. A.S. Kovo, O. Hernandez, S.M. Holmes, J. Mater. Chem. 19, 6207-6212 (2009)

24. E. Kłosek-Wawrzyna, J. Małolepszy, P. Murzyn, Proced. Eng. 57, 572-582 (2013)

25. E. Manias, A. Touny, L. Wu, K. Strawhecker, B. Lu, T.C. Chung, Chem. Mater. 13, 3516-3523 (2001)

26. S.S. Ray, M. Okamoto, Prog. Polym. Sci. 28, 1539-1641 (2003)

27. A. Leuteritz, D. Pospiech, B. Kretzschmar, M. Willeke, D. Jehnichen, U. Jentzsch, K. Grundke, A. Janke, Adv. Eng. Mater. 5, 678-681(2003)

28. P. Svoboda, C. Zeng, H. Wang, I.J. Lee, D.L. Tomasko, J. Appl. Polym. Sci. 85, 1562-1570 (2002)
29. Z. Vuluga, D.M. Panaitescu, C. Radovici, C. Nicolae, M.D. Iorga, Polym. Bull 69, 1073-1091(2012)

30. https://www.sparkfun.com/datasheets/Sensors/Flex/MSI-techman.pdf. Accessed 26 Jul 2016

31. N. Behrendt, V. Altstadt, H.W. Schmidt, X. Zhang, G.M. Sessler, IEEE Trans. Dielectr. Electr. Insul 13, 992-1000 (2006)

32. A. Mellinger, M. Wegener, W. Wirges, R. Mallepally, Ferroelectrics 331, 189-199 (2006) 